\title{
Size and geometry effects in notched compact tension specimens
}

DOI:

10.1016/j.ijpvp.2017.05.012

\section{Document Version}

Accepted author manuscript

Link to publication record in Manchester Research Explorer

\section{Citation for published version (APA):}

Horn, A. J., Sherry, A. H., \& Budden, P. J. (2017). Size and geometry effects in notched compact tension specimens. International Journal of Pressure Vessels and Piping, 154, 29-40.

https://doi.org/10.1016/j.jpvp.2017.05.012

\section{Published in:}

International Journal of Pressure Vessels and Piping

\section{Citing this paper}

Please note that where the full-text provided on Manchester Research Explorer is the Author Accepted Manuscript or Proof version this may differ from the final Published version. If citing, it is advised that you check and use the publisher's definitive version.

\section{General rights}

Copyright and moral rights for the publications made accessible in the Research Explorer are retained by the authors and/or other copyright owners and it is a condition of accessing publications that users recognise and abide by the legal requirements associated with these rights.

\section{Takedown policy}

If you believe that this document breaches copyright please refer to the University of Manchester's Takedown Procedures [http://man.ac.uk/04Y6Bo] or contact uml.scholarlycommunications@manchester.ac.uk providing relevant details, so we can investigate your claim.

\section{OPEN ACCESS}




\title{
Size and Geometry Effects in Notched Compact Tension Specimens
}

\author{
A J Horn*1, A H Sherry ${ }^{2,3}$, P J Budden ${ }^{4}$
}

1. Amec Foster Wheeler, 305 Bridgewater Place, Birchwood Park, Risley, Cheshire. WA3 6XG. UK.

2. National Nuclear Laboratory, Chadwick House, Warrington Road, Birchwood Park, Risley, Cheshire. WA3 6AE. UK.

3. Dalton Nuclear Institute, The University of Manchester, Pariser Building, Floor G, Sackville Street, Manchester, UK. M13 9PL.

4. EDF Energy, Barnett Way, Barnwood, Gloucester. GL4 3RS. UK.

* Corresponding Author, email: Anthony.Horn@amecfw.com 


\begin{abstract}
This paper uses Weibull stress analysis to investigate whether the effective notch toughness $K_{m a t}^{\rho}$ for cleavage fracture measured using Compact Tension (CT) specimens containing a U-notch is dependent on the size and geometry of the CT specimen. Notched CT specimens are typically used to measure a material's effective notch toughness $K_{\text {mat }}^{\rho}$ and to assess failure of a structure containing a non-sharp defect using the Notch Failure Assessment Diagram (NFAD). The paper concludes that $K_{m a t}^{\rho}$ is dependent on specimen thickness $B$ over and above the microstructural weakest link effect arising from differences in the volume of the plastic zone; $K_{m a t}^{\rho}$ is a function of not only the in-plane effect of the notch radius but also an out-of-plane constraint loss which itself is enhanced by the presence of the notch radius. This out-of-plane constraint loss can be more significant than the inplane effect of the notch radius. The use of experimentally measured $K_{m a t}^{\rho}$ values in an NFAD assessment of a notched structure may therefore be non-conservative if the out-of-plane constraint loss in the CT specimen is more significant than in the structure. For the material considered in this paper, doubling the thickness $B$ of the CT specimen resulted in plane strain conditions being sufficiently dominant to eliminate out-of-plane constraint loss in the CT specimen.
\end{abstract}

KEYWORDS: Blunt notch, effective fracture toughness, Notch Failure Assessment Diagram.

\title{
NOMENCLATURE
}

$a \quad$ Crack or notch depth (from the notch mouth to the tip of the notch)

$B \quad$ Specimen thickness

$b \quad$ Uncracked ligament ahead of the crack or notch, where $b=W-a$

E Elastic modulus

$f\left(L_{r}\right) \quad$ Failure assessment curve on the FAD

$f\left(L_{r}^{\rho}\right) \quad$ Failure assessment curve on the NFAD

Elastic-plastic energy release rate

$J^{\rho} \quad J$ for a notch

$J_{e} \quad$ Elastic component of $J$

$J_{p} \quad$ Plastic component of $J$

$J_{\text {ASTM }} \quad J$ obtained from load-displacement data using ASTM E1820, Equation 5

$K_{I} \quad$ Linear elastic stress intensity factor

$K_{I}^{\rho} \quad$ Linear elastic stress intensity factor for a notch

$K_{J} \quad J$ expressed in dimensions of $K$

$K_{J}^{\rho} \quad J^{\rho}$ expressed in dimensions of $K$

$K_{J C}^{\rho} \quad$ Critical value of $K_{J}^{\rho}$ for an individual test specimen containing a notch

$K_{m a t} \quad K_{J C}$ measured using pre-cracked specimens at a defined $P_{f}$

$K_{\text {mat }}^{\rho} \quad K_{J C}$ measured using notched specimens at a defined $P_{f}$

$K_{\min } \quad$ Minimum possible value of $K_{\text {mat }}$, taken as $20 \mathrm{MPa} \sqrt{\mathrm{m}}$

$K_{r} \quad$ Fracture ratio, plotted on y-axis of the FAD

$K_{r}^{\rho} \quad$ Fracture ratio for a notch, plotted on y-axis of the NFAD

$L \quad$ Element size defined in Figure 3

$L_{r} \quad$ Load ratio, plotted on the x-axis of the FAD

$L_{r}^{\rho} \quad$ Load ratio for a notch, plotted on $\mathrm{x}$-axis of the NFAD

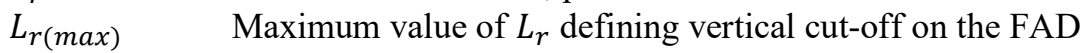

$m \quad$ Weibull modulus

$n \quad$ Strain hardening exponent

$r \quad$ Distance from the centre of curvature of the notch root radius in Figure 3

$P \quad$ Applied load

$P_{f} \quad$ Failure probability 


$\begin{array}{ll}P_{L} & \text { Limit load } \\ P_{L}^{\rho} & \text { Limit load for a notch } \\ Q & \text { Measure of constraint for extended yielding } \\ T \text {-stress } & \text { Measure of constraint for contained yielding } \\ T & \text { Temperature } \\ T_{0} & \text { Master Curve Reference Temperature } \\ U_{p} & \text { Plastic component of the area under the load vs. displacement curve } \\ V & \text { Plastic zone } \\ V_{0} & \text { Reference volume taken as unity } \\ W & \text { Specimen width } \\ x_{1}, x_{2}, x_{3} & \text { Co-ordinate system in Figures } 2 \text { and } 3 \\ Y & \text { Geometry factor used to define } K_{I} \\ \gamma & \text { Material parameter describing sensitivity of } K_{m a t}^{\rho} / K_{m a t} \text { to } \sigma_{N} / \sigma_{y} \\ \varepsilon & \text { Applied strain } \\ \varepsilon_{0} & \text { Strain at the limit of proportionality } \\ \eta_{p} & \text { Plastic component of the proportionality constant to evaluate } J \text { from load vs. } \\ v & \text { displacement } \\ \rho & \text { Poisson's ratio } \\ \theta & \text { Notch root radius } \\ \sigma & \text { Angle subtended at the centre of curvature of the notch root radius in Figure } 3 \\ \bar{\sigma} & \text { Applied tensile stress } \\ \sigma_{1} & \text { Flow stress, defined as the mean of } \sigma_{y} \text { and UTS } \\ \sigma_{N} & \text { Maximum principal stress } \\ \sigma_{0} & \text { Elastic notch tip opening stress } \\ \sigma_{u} & \text { Stress at the limit of proportionality } \\ \sigma_{w} & \text { Weibull parameter, defined as } \sigma_{w} \text { at } P_{f}=0.632 \\ \sigma_{y} & \text { Weibull stress } \\ 1 \mathrm{~T} & \text { Yield stress defined at } 0.2 \% \text { plastic strain } \\ 0.5 \mathrm{~T} & \text { Code used to define specimen dimensions } B=25 \mathrm{~mm}, W=50 \mathrm{~mm}, a=25 \mathrm{~mm} \\ 0.25 \mathrm{~T} & \text { Code used to define specimen dimensions } B=12.5 \mathrm{~mm}, W=25 \mathrm{~mm}, a=12.5 \mathrm{~mm} \\ \mathrm{CT} & \text { Code used to define specimen dimensions } B=6.25 \mathrm{~mm}, W=12.5 \mathrm{~mm}, a=6.25 \mathrm{~mm} \\ \mathrm{FAD} & \text { Compact Tension } \\ \mathrm{FE} & \text { Failure Assessment Diagram } \\ \mathrm{NFAD} & \text { Finite Element } \\ \mathrm{PS} & \text { Notch Failure Assessment Diagram } \\ \mathrm{SEM} & \text { Plane strain } \\ \mathrm{SSY} & \text { Scanning Electron Microscopy } \\ \mathrm{SSY} & \text { Small Scale Yielding } \\ \mathrm{UTS} & \text { Small Scale Yielding for a notch } \\ & \text { Ultimate Tensile Stress } \\ & \end{array}$

\section{INTRODUCTION}

The structural integrity of engineering structures is conventionally assessed using defect or flaw assessment procedures based on fracture mechanics approaches [e.g. 1-3]. For a real or postulated defect, the crack driving force (e.g. the elastic-plastic energy release rate $J$ or the elastic-plastic stress intensity factor $K_{J}$ ) under the loading conditions and temperature of interest is compared with the material fracture toughness. Such procedures assume flaws to be infinitely sharp. While this assumption may be appropriate for fatigue cracks, in other cases such as porosity, lack-of-fusion, corrosion damage, mechanical damage, or even design features such a crevices in tube-to-tubeplate assemblies, it can be an over-conservative assumption that can lead to a pessimistic assessment of the structure and a significant under-estimation of the safety margin against fracture. 
Structural integrity assessments undertaken in accordance with [1-3] are carried out using a Failure Assessment Diagram (FAD) in which the ordinate $K_{r}$ indicates the proximity to fracture. $K_{r}$ is defined as $K_{I} / K_{\text {mat }}$, where $K_{I}$ is the linear elastic stress intensity factor and $K_{m a t}$ is the material toughness typically derived from fatigue pre-cracked fracture toughness specimens tested according to welldefined standards, e.g. [4-6]. The abscissa $L_{r}$ indicates the proximity to failure by plastic collapse and is defined as $P / P_{L}$, where $P$ is the applied load and $P_{L}$ is the elastic-perfectly plastic limit load. $K_{r}$ and $L_{r}$ are both proportional to $P$ and a linear loading line can be plotted on the FAD. When all inputs are best-estimate values, failure is predicted at its intersection with the failure assessment curve which is represented by $K_{r}=f\left(L_{r}\right)$ for $L_{r}<L_{r(\max )}$ where $f\left(L_{r}\right)$ is the failure assessment curve, $L_{r(\max )}$ is the ratio of the uniaxial flow stress $\bar{\sigma}$ to the uniaxial yield stress $\sigma_{y}$ defined at $0.2 \%$ plastic strain, and $\bar{\sigma}$ is defined as the mean of $\sigma_{y}$ and the ultimate tensile stress UTS.

Over the last 25 years or so, several engineering assessment methodologies have been published in the literature for assessing structures that contain non-sharp defects using a modified form of the FAD called the Notch Failure Assessment Diagram (NFAD) [e.g. 7-12]. The exact form of the NFAD varies from approach to approach. Taking the approach described in [7] and [12] as an example, proximity to the two failure limits of plastic collapse and fracture is quantified by the parameters $L_{r}^{\rho}$ and $K_{r}^{\rho} . L_{r}^{\rho}$ is defined as $P / P_{L}^{\rho}$, where $P_{L}^{\rho}$ is the elastic-perfectly plastic limit load for a component containing a notch of root radius $\rho . K_{r}^{\rho}$ is defined as $K_{I}^{\rho} / K_{\text {mat }}^{\rho}$, where $K_{I}^{\rho}$ is the linear-elastic notch stress intensity factor and $K_{m a t}^{\rho}$ is the effective notch toughness. The condition that the component does not fail is indicated by $K_{r}^{\rho}<f\left(L_{r}^{\rho}\right)$ for $L_{r}^{\rho}<L_{r(\max )}$. Several authors $[7,12,13]$ have shown that when the NFAD axes are defined by $L_{r}^{\rho}$ and $K_{r}^{\rho}$ instead of $L_{r}$ and $K_{r}$, failure assessment curves are broadly independent of $\rho$. This enables the same failure assessment curve to be used in the NFAD as for the FAD.

Although the precise definitions of the parameters used in the various forms of NFAD vary between the different approaches, one similarity common to all NFAD approaches is the requirement to use an effective notch toughness $K_{m a t}^{\rho}$ in place of the material toughness $K_{m a t}$, to calculate $K_{r}^{\rho}$. No testing standards are currently available to provide guidance on how $K_{m a t}^{\rho}$ can be measured using fracture toughness specimens that contain notches instead of pre-cracks. In the absence of dedicated test standards for notched specimens, test standards originally designed for pre-cracked specimens such as [4-6] have been used widely in the literature [e.g. 7, 11, 16-21] to obtain values of $K_{\text {mat }}^{\rho}$ for notched specimens. It has recently been shown $[14,15]$ that in most cases, such testing standards can provide reasonably accurate values of $K_{m a t}^{\rho}$ for notched specimens. However, to the authors' knowledge no work has yet been undertaken to investigate whether the values of $K_{m a t}^{\rho}$ measured on laboratory specimens are independent of the size and geometry of the test specimen, and hence whether such $K_{m a t}^{\rho}$ values are transferable for use in NFAD approaches to assess the integrity of structures containing non-sharp defects.

The objective of the work presented in this paper is to investigate whether $K_{m a t}^{\rho}$ values for cleavage fracture measured using Compact Tension (CT) specimens containing notches instead of fatigue precracks are dependent on the size and geometry of the CT specimen.

\section{BACKGROUND}

The NFAD approaches in [7-12] describe the increase in effective notch toughness either as a function of $\rho$, or another parameter that characterises the notch radius. The approach described in [12] relates $K_{m a t}^{\rho}$ to the component of the elastic notch tip stress $\sigma_{N}$ acting in a direction perpendicular to the plane of the notch. $\sigma_{N}$ scales with load: a given value of $\sigma_{N}$ could correspond to an acute notch under low load, or a blunter notch subject to a higher load. An expression for $\sigma_{N}$ was derived by Shin [23] 
based on the Creager-Paris elastic stress distribution ahead of a slender notch in a uniform stress field [24]:

$$
\sigma_{N}=\sigma\left(1+2 Y \sqrt{\frac{a}{\rho}}\right)
$$

where $\sigma$ is the applied tensile stress remote from the notch and $Y$ is a geometry factor used to define $K_{I}$. The following empirical power law expression was found to describe the increase in effective cleavage toughness with increasing notch radius in [12], and preliminary work in [25] indicated that the same expression may be used to describe the increase in ductile tearing initiation toughness with notch radius:

$$
\frac{K_{m a t}^{\rho}}{K_{m a t}}=1+\gamma\left[\frac{\sigma_{N}}{\sigma_{y}}\right]^{-l}
$$

where $\gamma$ and $l$ are non-dimensional material parameters that describe the sensitivity of material toughness to the notch root radius. Equation 2 defines the failure locus shown in Figure 1. A loading line may be plotted on the diagram for a notched component of interest, with failure being predicted by its intersection with the failure locus. For the loading lines, the vertical axis is defined as $K_{J}^{\rho} / K_{\text {mat }}$ where $K_{J}^{\rho}$ is $J$ for a notch, $J^{\rho}$, expressed in dimensions of $K$. For blunt notches the loading curve rises steeply and failure is predicted at high $K_{m a t}^{\rho}$ values, and for acute notches the loading curve is less steep and failure is predicted at lower $K_{m a t}^{\rho}$ values. As $\rho \rightarrow 0$, the gradient of the failure locus at its intersection with the loading line approaches the horizontal and $K_{m a t}^{\rho} \rightarrow K_{m a t}$.

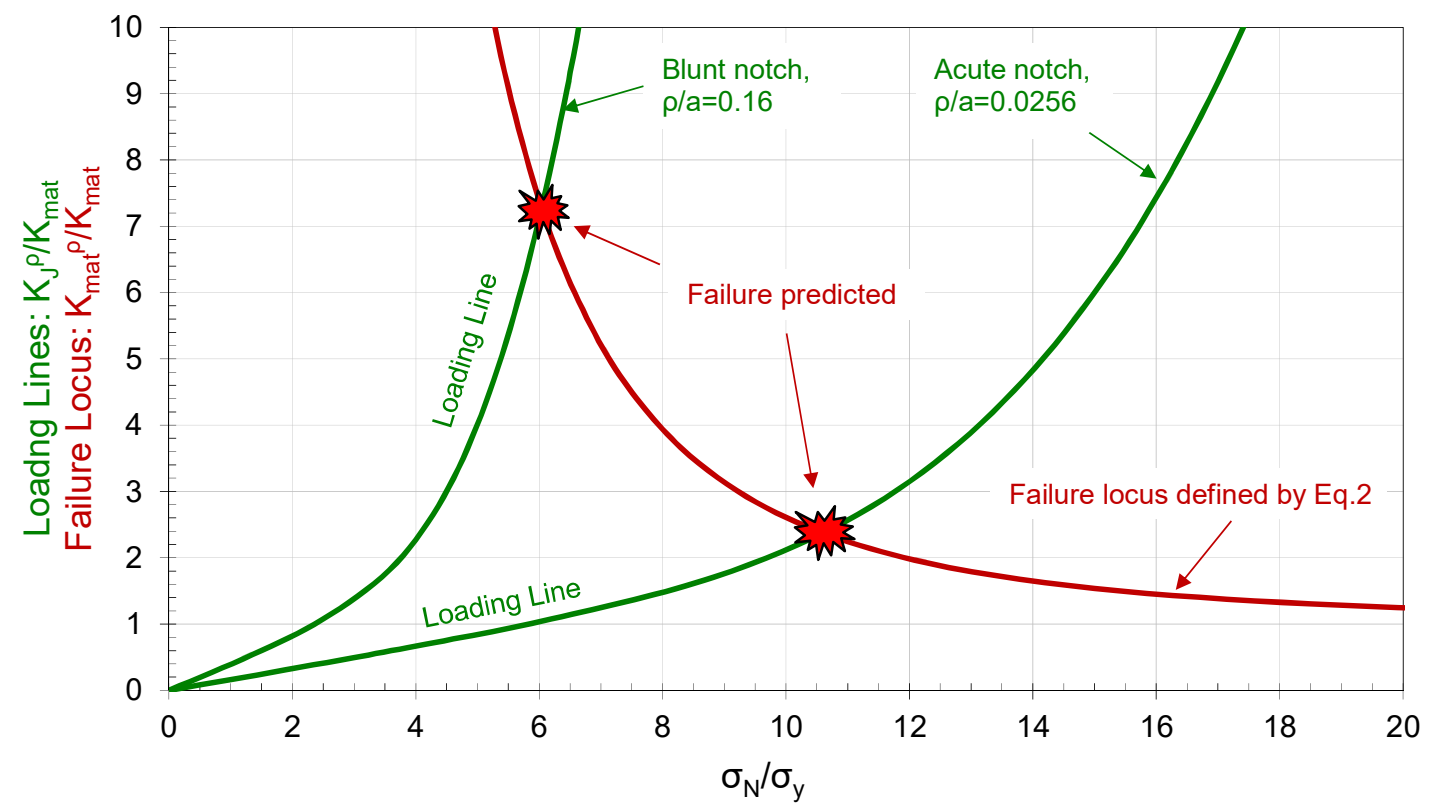

Figure 1: Loading lines and failure locus in toughness- $\sigma_{N}$ space

Depending on failure mechanism, values of $\gamma$ and $l$ that define the failure locus in Figure 1 can be obtained using one of several methods:

(a) For initiation by cleavage and ductile tearing, curve fitting to test data plotted in the form of $K_{J C}^{\rho} / K_{\text {mat }}$ vs. $\sigma_{N} / \sigma_{y}$ can be performed, where $K_{J C}^{\rho}$ is the value of $K_{J}^{\rho}$ at failure for an individual test specimen containing a notch. This is straightforward for cleavage fracture, but 
is less so for ductile tearing initiation due to the lack of test guidance and the practical challenges of measuring and defining tearing initiation from a notch tip.

(b) For initiation by cleavage only, the lookup table presented in [12] can be used based on a knowledge of Weibull modulus $m$ and strain hardening exponent $n$.

(c) For initiation by cleavage only, a combination of (a) and (b) can be used, useful for when $m$ is unknown but $n$ is known.

(d) For initiation by cleavage and ductile tearing, micromechanical modelling using an appropriate local approach failure criterion can be used.

The lookup table for use in option (b) requires a knowledge of the Weibull modulus $m$, a parameter used in the Beremin model [26] which describes the proximity to cleavage fracture by use of the scalar Weibull stress, $\sigma_{w}$. In its simplest form the probability of fracture $P_{f}$ is described by a twoparameter Weibull distribution:

$$
P_{f}=1-\exp \left[-\left(\frac{\sigma_{w}}{\sigma_{u}}\right)^{m}\right]
$$

where $\sigma_{u}$ and $m$ are the Weibull parameters. The Weibull stress is calculated by integrating a weighted value of the maximum principal stress $\sigma_{1}$ over the plastic zone $V$ ahead of the stress concentration:

$$
\sigma_{w}=\left[\frac{1}{V_{0}} \int_{V} \sigma_{1}^{m} d V\right]^{1 / m}
$$

The constant $V_{0}$ is a reference volume required to ensure dimensional consistency and in the current work is take as unity. The Weibull parameters $m$ and $\sigma_{u}$ are determined by matching values calculated from the Beremin model to experimental values of cleavage fracture toughness. Reliable estimation of the Weibull parameters is only possible using experimental data of sufficient quantity that cover two different constraint levels. The method proposed by Gao et al [27] provides a suitable methodology.

The lookup table for values of $\gamma$ and $l$ presented in [12] was generated using Weibull stress analysis of boundary layer models containing notches instead of fatigue pre-cracks. A full description of the method used can be found in [12] and is not repeated here. As a consequence of using boundary layer models, failure loci described using values of $\gamma$ and $l$ obtained from the lookup table are relevant for notches in infinite solids, where the free surfaces are sufficiently far away such that the notch tip stress fields are unaffected. The combined condition of both plane strain and Small Scale Yielding (SSY) for a notch that are simultaneously present in the boundary layer model is referred to in this paper as $\mathrm{SSY}^{\mathrm{N}}$ for short. The intent of using this terminology is to clearly distinguish this condition from that in a notched compact tension specimen modelled in plane strain.

\section{METHODOLOGY}

\subsection{Finite Element Analysis}

The three-dimensional (3D) finite element (FE) models used in the current work were originally developed and validated as part of the work presented in [15]. Three different sizes of standard thickness CT specimens were modelled denoted as $1 \mathrm{~T}, 0.5 \mathrm{~T}$ and $0.25 \mathrm{~T}$ corresponding to specimen thicknesses $B$ of $25 \mathrm{~mm}, 12.5 \mathrm{~mm}$ and $6.25 \mathrm{~mm}$ respectively. In all standard thickness specimens modelled, $B=W / 2$ where $W$ is the specimen width measured from the load line (i.e. the centre of the loading pins) to the base of the specimen, and $a / W=0.5$ where $a$ is the notch depth defined as the distance from the load line to the tip of the notch. For each specimen size (1T, 0.5T and 0.25T), four 
models were constructed, each containing a U-notch of a different $\rho$, resulting in a total of twelve 3D FE model geometries of standard thickness CT specimens. The four notch radii modelled were $\rho / a=$ $0.0256,0.04,0.08$ and 0.16 ; pre-cracked specimens were not analysed as part of this work. It is not possible to model or test CT specimens with $\rho / a$ values significantly larger than 0.16 due to the geometrical constraints arising from the holes through which the loading pins are inserted. An example of a CT specimen with $\rho / a=0.16$ is shown in Figure 2(a). In addition to these 3D analyses, the models were also run with additional boundary conditions specified on the free surface to restrict out-of-plane displacement, effectively creating a set of twelve 2D plane strain analyses but using the same 3D models.

Non-standard double-thickness CT specimens were also modelled and analysed; an example of a double-thickness CT specimen with $\rho / a=0.16$ is shown in Figure 2(b). These specimens were identical to the standard thickness $C$ T specimens except that the specimen thickness $B$ was set equal to $W$, i.e. double the thickness of a standard CT specimen. The change in thickness was achieved by doubling the extrusion depth, so the standard and double thickness models had the same number of elements in the thickness direction. The double-thickness CT specimens were analysed in 3D as well as in plane strain by imposing boundary conditions on the free surfaces to restrict out-of-plane displacement. The overall matrix of $48 \mathrm{FE}$ models is provided in Table 1. FE analyses were performed using ABAQUS version 6.12-1 [28].
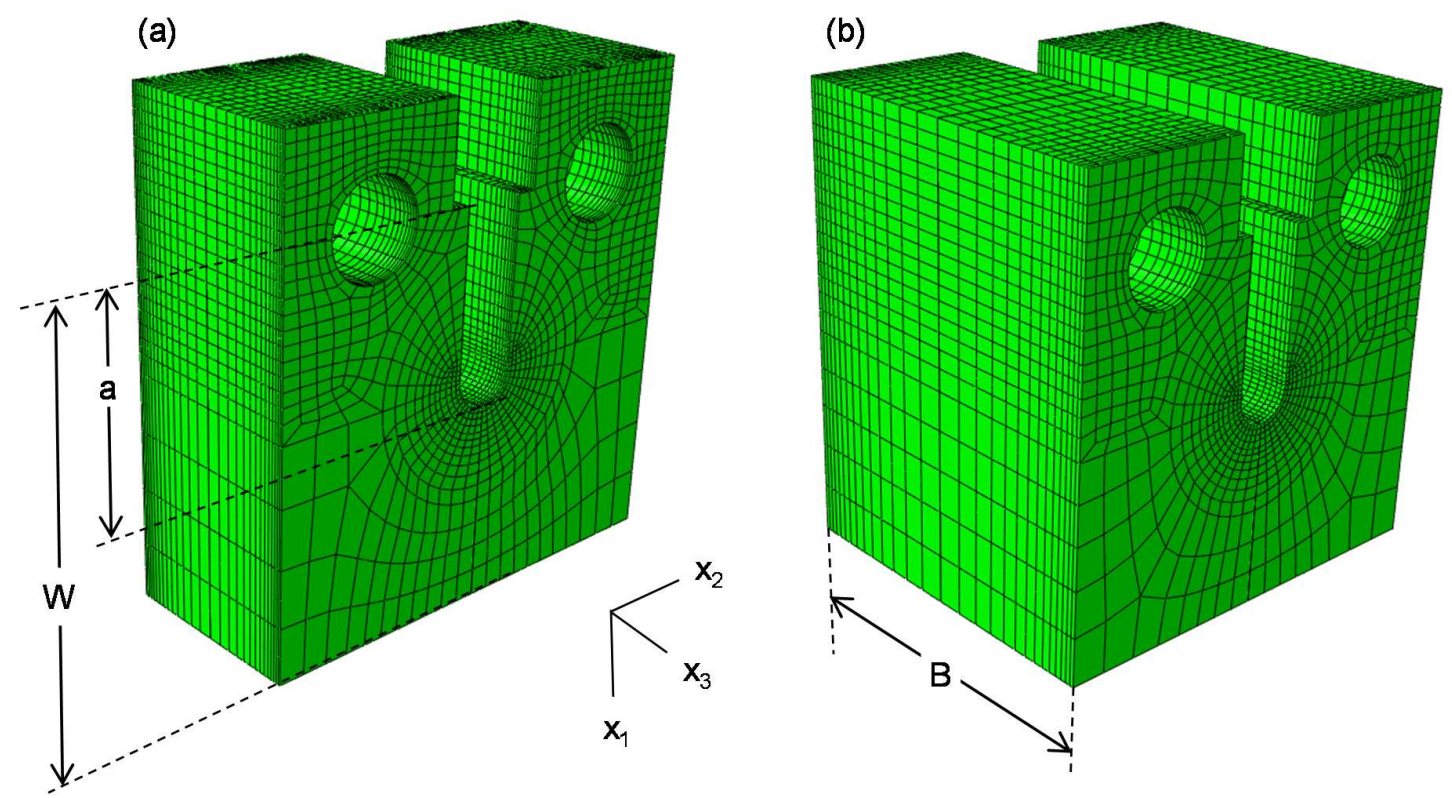

Figure 2: (a) Standard, and (b) double thickness CT specimens with $\rho / a=0.16$. Note these images are of the full CT specimens; only one quarter of each specimen was modelled numerically.

Table 1: Matrix of 48 FE models (PS stands for Plane Strain)

\begin{tabular}{|l|l|l|l|l|}
\hline $\begin{array}{l}\text { Short Model Name } \\
(\mathbf{P S}=\text { Plane Strain) }\end{array}$ & $\begin{array}{l}\boldsymbol{B} \\
\mathbf{( m m})\end{array}$ & $\begin{array}{l}\boldsymbol{W} \\
\mathbf{( m m})\end{array}$ & $\begin{array}{l}\boldsymbol{a} \\
\mathbf{( m m})\end{array}$ & $\boldsymbol{\rho} / \boldsymbol{a}$ \\
\hline Standard 1T - 3D & 25 & 50 & 25 & $0.0256,0.04,0.08,0.16$ \\
\hline Standard 1T - PS & 25 & 50 & 25 & $0.0256,0.04,0.08,0.16$ \\
\hline Standard 0.5T - 3D & 12.5 & 25 & 12.5 & $0.0256,0.04,0.08,0.16$ \\
\hline Standard 0.5T - PS & 12.5 & 25 & 12.5 & $0.0256,0.04,0.08,0.16$ \\
\hline Standard 0.25T - 3D & 6.25 & 12.5 & 6.25 & $0.0256,0.04,0.08,0.16$ \\
\hline Standard 0.25T - PS & 6.25 & 12.5 & 6.25 & $0.0256,0.04,0.08,0.16$ \\
\hline Thick 1T - 3D & 50 & 50 & 25 & $0.0256,0.04,0.08,0.16$ \\
\hline Thick 1T - PS & 50 & 50 & 25 & $0.0256,0.04,0.08,0.16$ \\
\hline Thick 0.5T - 3D & 25 & 25 & 12.5 & $0.0256,0.04,0.08,0.16$ \\
\hline Thick 0.5T - PS & 25 & 25 & 12.5 & $0.0256,0.04,0.08,0.16$ \\
\hline
\end{tabular}




\begin{tabular}{|l|l|l|l|l|}
\hline Thick $0.25 \mathrm{~T}-3 \mathrm{D}$ & 12.5 & 12.5 & 6.25 & $0.0256,0.04,0.08,0.16$ \\
\hline Thick $0.25 \mathrm{~T}-\mathrm{PS}$ & 12.5 & 12.5 & 6.25 & $0.0256,0.04,0.08,0.16$ \\
\hline
\end{tabular}

For each CT specimen modelled, symmetry conditions were specified along the uncracked ligament $\left(x_{2}=0\right)$ and the longitudinal mid-plane $\left(x_{3}=\mathrm{B} / 2\right)$ thereby enabling one quarter of each $\mathrm{CT}$ specimen to be modelled numerically. Each model consisted of quadratic 20-noded reduced integration hexahedral elements (C3D20R) arranged into 14 variable thickness layers. The thickest element layer was defined at the longitudinal mid-plane with thinner elements defined near the free surface to accommodate the reduced constraint approaching plane stress conditions. Each model had a straight notch front.

Within each of the 14 variable thickness layers, rings of elements enclosed the notch tip as shown in Figure 3. The notch tip elements had a dimension $L$ in the $x_{1}$ direction and a dimension approximately equal to $L$ in the angular direction, $\theta=\tan ^{-1}\left(x_{2} / x_{1}\right)$. In the angular direction, 10 equally sized elements were defined in the range $0<\theta<\pi / 2$ and $L$ was constant with $\theta$. In the $x_{1}$ direction, $L$ increased with increasing distance $r$ from the centre of curvature of the notch tip, where $L=2 \pi r / 40$. The ratio $\rho / L$ was therefore the same in all models and ensured a consistency of mesh structures between models with notches of differing radii.

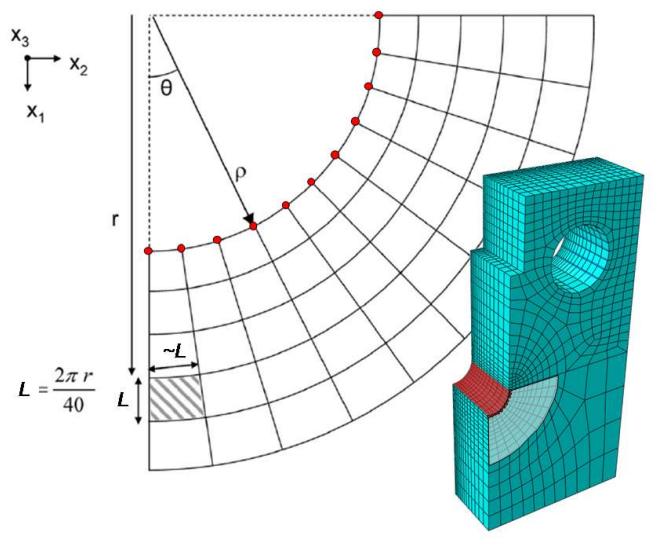

Figure 3: Notch tip mesh and one-quarter FE model of a standard thickness CT specimen.

The loading pin was modelled using a three-dimensional rigid analytical part in the shape of a cylinder positioned within the hole of the CT specimen. Loading in tension was simulated by applying a prescribed displacement in the $x_{2}$ direction to a single reference point tied to the loading pin. This enabled the reaction force to be evaluated through the single reference point. Rotation of the loading pin was prevented by setting all degrees of freedom, other than the displacement in the $x_{2}$ direction, to zero.

The tensile data used as an input to the FE models were for a $35 \mathrm{~mm}$ thick roller-quenched and tempered structural steel grade S690Q which was given a non-standard heat treatment designed to promote brittle fracture at room temperature. Plasticity was modelled using true-stress vs. true-strain data obtained from tensile tests performed at $0^{\circ} \mathrm{C}$ for the initial part of the stress-strain curve, then a Ramberg-Osgood extrapolation to the test data for higher strains. The yield strength $\sigma_{y}$ defined at $0.2 \%$ plastic strain was $430 \mathrm{MPa}$ and the strain hardening exponent $n$ used to extrapolate the stressstrain curve to high strains was derived as 6.4. More details of the material, heat treatment and resulting tensile and toughness properties are provided in [22] which also describes the methodology adopted for calibrating the Weibull modulus $m$, calculated to be $m=19.9$ at $0^{\circ} \mathrm{C}$. In this paper, a value of $m=20.0$ has been selected for the simplicity of using the lookup table in [12].

\subsection{Post-processing}


To calculate the Weibull stress $\sigma_{w}$, numerical data (maximum principal stresses and integration point volumes) were post-processed from each FE model to define the evolution of $\sigma_{w}$, calculated using Equation 4, with $J_{A S T M}$, calculated using Equation 5:

$$
J_{A S T M}=J_{e}+J_{p}=\frac{K_{I}^{2}\left(1-v^{2}\right)}{E}+\frac{\eta_{p} U_{p}}{B(W-a)}
$$

where $J_{e}=$ elastic component of $J$

$J_{p}=$ plastic component of $J$

$K_{I}=$ linear elastic stress intensity factor defined in ASTM E1820 [5]

$v=$ Poisson's ratio

$E=$ elastic modulus

$\eta_{p}=2+0.522(1-a / W)$ for CT specimens

$U_{p}=$ plastic component of area under load vs. displacement curve

Although Equation 5 was derived for use with pre-cracked specimens, it was shown in [15] that $J_{A S T M}$ provides reasonable estimates of $J$ for a notch, $J^{\rho}$, typically to within 5 or $10 \%$ depending on specimen geometry and loading level. An example plot of $\sigma_{w}$ vs. $J_{A S T M}$ is shown in Figure 4(a). The probability of fracture is directly related to $\sigma_{w}$ via Equation 3. Therefore a horizontal line plotted in Figure 4(a) defines a particular cleavage fracture probability. Figure 4(b) shows the corresponding plot of cleavage fracture probability as a function of $J_{A S T M}$ for a range of FE models. Figure 4 shows a clear size effect between the $1 \mathrm{~T}, 0.5 \mathrm{~T}$ and $0.25 \mathrm{~T}$ specimens that contain the bluntest notch modelled. For example, Figure 4(b) shows that the 1T specimen with $\rho / a=0.16$ achieves a cleavage fracture probability of $50 \%$ at an applied $J_{A S T M}$ of $800 \mathrm{~kJ} / \mathrm{m}^{2}$, whereas the $0.25 \mathrm{~T}$ specimen with the same $\rho / a$ must be loaded to around twice that value of $J_{A S T M}$ to achieve the same probability of cleavage fracture. The size effect becomes less significant with decreasing $\rho / a$, and almost vanishes for the most acute $\rho / a$ modelled.
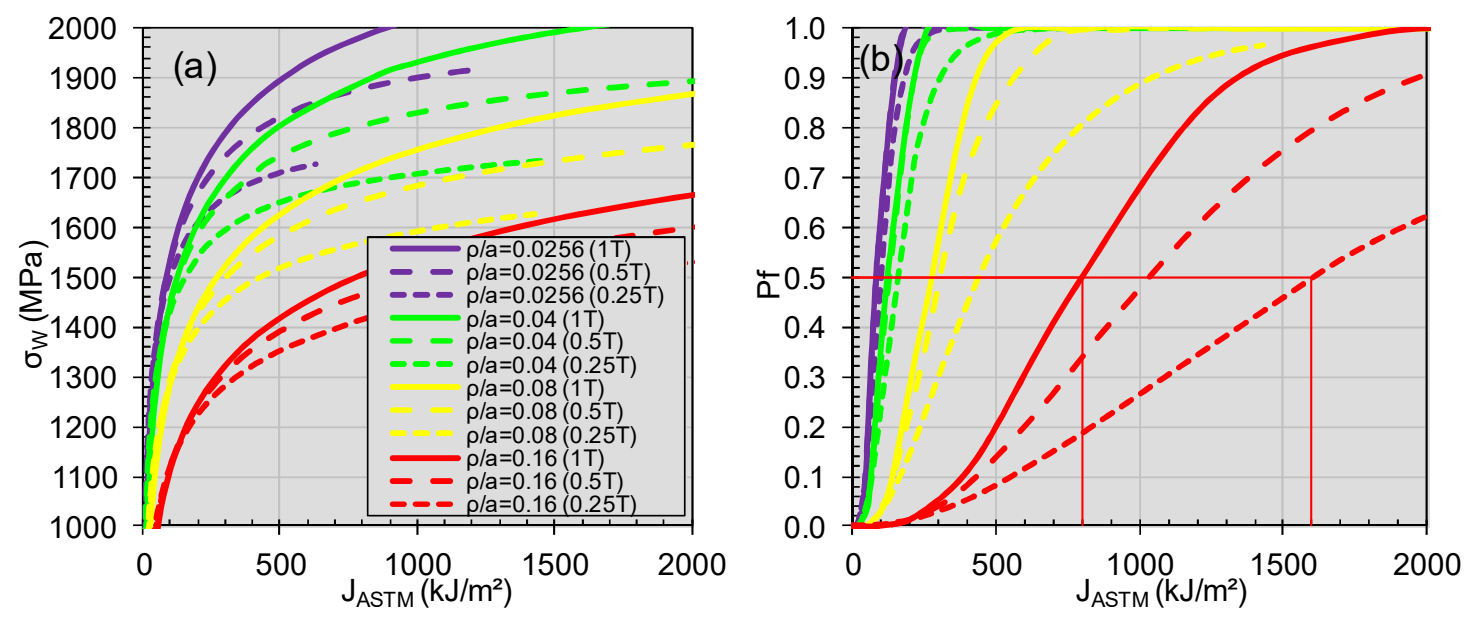

\section{Figure 4: Evolution of (a) Weibull stress, and (b) cleavage fracture probability with $\mathbf{J}_{\text {ASTM }}$ for} $1 \mathrm{~T}, 0.5 \mathrm{~T}$ and $0.25 \mathrm{~T} \mathrm{CT}$ specimens containing notches of varying $\rho / \mathrm{a}$

Loading lines were also plotted in the form of $K_{J}^{\rho} / K_{\text {mat }}$ vs. $\sigma_{N} / \sigma_{y}$. The elastic notch tip stress $\sigma_{N}$ was calculated using Equation 1 with $\sigma=P /(B(W-a))$ and $Y=3.8534$ for $a / W=0.5$. To calculate $K_{J}^{\rho}$, it was first assumed that $J_{A S T M}$ provides a reasonable estimate of $J^{\rho}$ as shown in [15]. $K_{J}^{\rho}$ was then obtained using the expression $K_{J}^{\rho}=\sqrt{J^{\rho} E /\left(1-v^{2}\right)}$. 
The values of $K_{\text {mat }}$ used to normalise $K_{J}^{\rho}$ were taken from the toughness properties of the modified S690Q plate reported in [22] which had been given a non-standard heat treatment designed to promote brittle fracture at room temperature. The Master Curve [29] Reference Temperature $T_{0}$, defined as the temperature at which the median fracture toughness for a $25 \mathrm{~mm}$ thick specimen is $100 \mathrm{MPa} \sqrt{\mathrm{m}}$, was measured as $+49^{\circ} \mathrm{C}$. The Master Curve provides a basis for the determination of $K_{\text {mat }}$ at any cleavage fracture probability over a range of temperatures in the transition region. In this approach $K_{\text {mat }}$ is defined by:

$$
K_{\text {mat }}=\left[\ln \frac{1}{1-P_{f}}\right]^{1 / 4}\left(11+77 \exp \left\{0.019\left(T-T_{0}\right)\right\}\right)\left(\frac{25}{B}\right)^{1 / 4}+K_{\text {min }}
$$

where $T$ is the temperature in ${ }^{\circ} \mathrm{C}, K_{\min }$ is $20 \mathrm{MPa} \sqrt{\mathrm{m}}$, and $B$ is in units of millimetres. Values of $K_{\text {mat }}$ used to normalise $K_{J}^{\rho}$ were calculated at $T=0^{\circ} \mathrm{C}, P_{f}=0.5$, and the specific crack front length (equal to the CT specimen thickness $B$ ) for the relevant CT specimen geometry as summarised in Table 1, i.e. in the range $6.25<B<50 \mathrm{~mm}$. Equation 6 assumes plane strain conditions; its accuracy would therefore be expected to reduce for specimens that are sufficiently thin that plane strain conditions no longer dominate the crack-tip region. Fracture toughness testing standards such as [5] provide minimum thickness requirements to ensure plane strain conditions dominate in fatigue pre-cracked specimens. For the relevant material properties and $K_{m a t}$ value predicted by Equation 6 for the thinnest compact tension specimen of $B=6.25 \mathrm{~mm}$, the minimum thickness requirement is met, albeit with a relatively small margin. In terms of temperature, the Master Curve approach is restricted to failure by cleavage fracture in the range $-50<T-T_{0}<50^{\circ} \mathrm{C}$, hence the $T-T_{0}$ value of $-49^{\circ} \mathrm{C}$ considered in this work is at the lower end of the valid temperature range of the Master Curve. The lower temperature limit prevents the Master Curve being applied to data generated at temperatures on the lower shelf where there is a change in failure mechanism from cleavage caused by a single initiating microstructural feature to fracture caused by multiple initiating sites. Such lower shelf fractures are not described by the weakest link statistics of the Master Curve. For the material used in this study, detailed post-test fractography using Scanning Electron Microscopy (SEM) on selected specimens tested at $0^{\circ} \mathrm{C}$ was reported in [22]. This confirmed the presence of a single cleavage initiating site in each specimen studied, providing confidence that cleavage fracture is controlled by a weakest link mechanism and that the use of Equation 6 is appropriate. $K_{\text {mat }}$ values relevant for ductile tearing initiation are not dependent on crack front length; Equation 6 is therefore not valid for upper shelf behaviour.

Figure 5 shows plots of the loading curves $K_{J}^{\rho} / K_{\text {mat }}$ vs. $\sigma_{N} / \sigma_{y}$ for three sizes of CT specimen. The pattern of dashed lines used in Figure 5 is consistent with that used in Figure 4. The position on each loading curve at which $P_{f}=0.5$ was identified, resulting in one 'failure point' for each loading curve, indicated by the solid symbols. Equation 2 was then curve fitted through the failure points to determine the values of $\gamma$ and $l$. The curve fitting was achieved by first re-arranging Equation 2 such that it is in a form suitable for fitting a straight line, Equation 7. Note that $K_{m a t}^{\rho}$ in Equation 2 has been replaced by $K_{J C}^{\rho}$ in Equation 7, as the equation is intended for plotting individual test results:

$$
\ln \left(\frac{K_{J C}^{\rho}}{K_{m a t}}-1\right)=\ln \gamma-l \ln \left(\frac{\sigma_{N}}{\sigma_{y}}\right)
$$


The failure points were plotted in the form of Equation 7, i.e. with value of $\ln \left(\left[K_{J C}^{\rho} / K_{\text {mat }}\right]-1\right)$ plotted on the ordinate axis and value of $\ln \left(\sigma_{N} / \sigma_{y}\right)$ plotted on the abscissa axis. A straight line was fitted using the least squares method to obtain values of $\gamma$ and $l$, where the gradient of the line is equal to $-l$ and the intercept equal to $\ln (\gamma)$. The resulting failure locus using the values of $\gamma$ and $l$ in Equation 2 is plotted in black in Figure 5 for each of the three sizes of CT specimen.

The maximum and minimum values of $\rho / a$ that were modelled, 0.16 and 0.0256 , result in predicted $K_{m a t}^{\rho} / K_{\text {mat }}$ ratios of approximately eight and two respectively as shown in Figure 5. Curve fits shown outside this range are therefore extrapolations. The results presented in Section 4, Results and Discussion, show extrapolated curves as a means to indicate overall trends. However the extrapolated nature of these curves at high and low $K_{\text {mat }}^{\rho} / K_{\text {mat }}$ ratios should be noted.
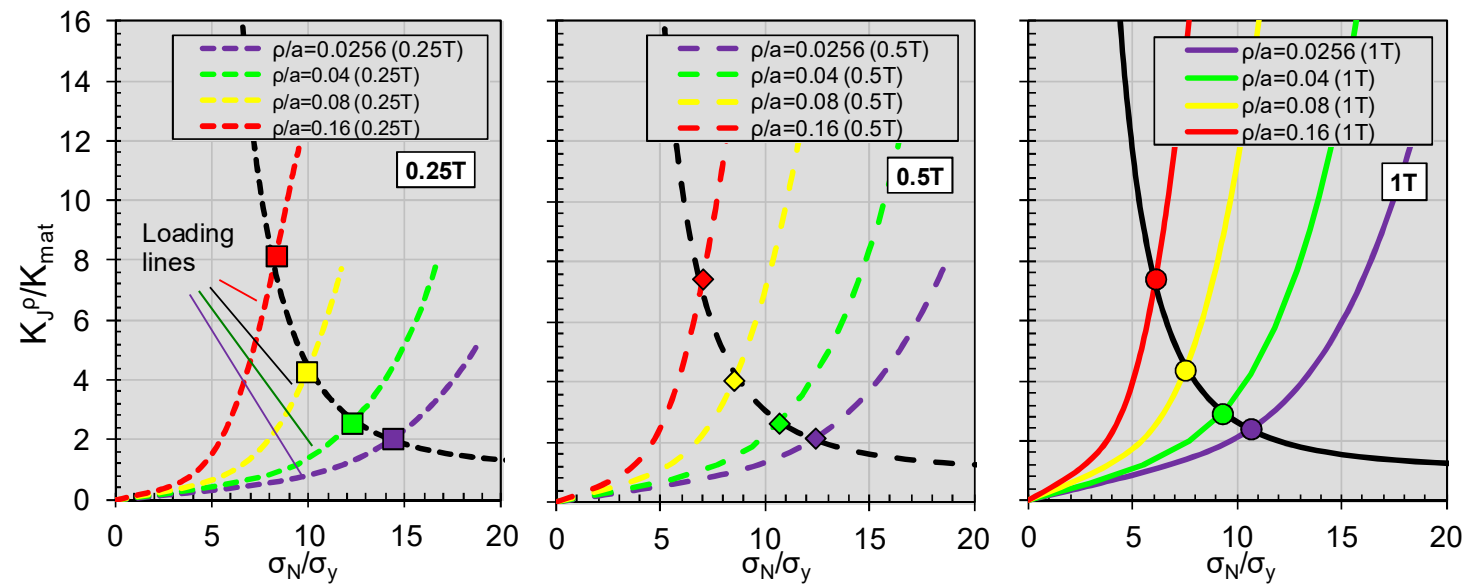

Figure 5: Loading lines and failure loci derived from Weibull stress analysis, plotted in $K_{\text {mat }}^{\rho} / K_{\text {mat }}$ vs. $\sigma_{N} / \sigma_{y}$ space.

\section{RESULTS AND DISCUSSION}

\subsection{Standard thickness CT specimens}

The failure loci for standard thickness $1 \mathrm{~T}, 0.5 \mathrm{~T}$ and $0.25 \mathrm{~T}$ specimens are plotted on the same axes in Figure 6, together with the failure locus defined by the lookup table which corresponds to Small Scale Yielding for a notch $\left(\mathrm{SSY}^{\mathrm{N}}\right)$. Using the lookup table in [12], $m=20$ and $n=6.4$ results in values of $\gamma$ and $l$ of 74.1 and 1.90 respectively. The regions of the graph where the failure loci have been extrapolated are labelled, and loading lines for $\rho / a=0.16$ for the three specimen sizes are also plotted.

To distinguish between the effects of notch radius and of specimen size, loading lines can be compared with the relevant failure loci. Taking the example of the $0.25 \mathrm{~T}$ specimen, the loading line intersects the $\mathrm{SSY}^{\mathrm{N}}$ failure locus relevant for a notch in an infinite solid at $K_{m a t}^{\rho} / K_{\text {mat }} \sim 3$, and the relevant failure locus for the $0.25 \mathrm{~T}$ test specimen at $K_{\text {mat }}^{\rho} / K_{\text {mat }} \sim 8$. This indicates that less than half of the observed enhancement in toughness is directly due to the effect of the notch radius; most of the observed toughness enhancement in this case is due to the specimen size effect. For the 1T specimen, the notch radius effect and specimen size effect contribute to the overall $K_{m a t}^{\rho}$ in roughly equal proportions. 


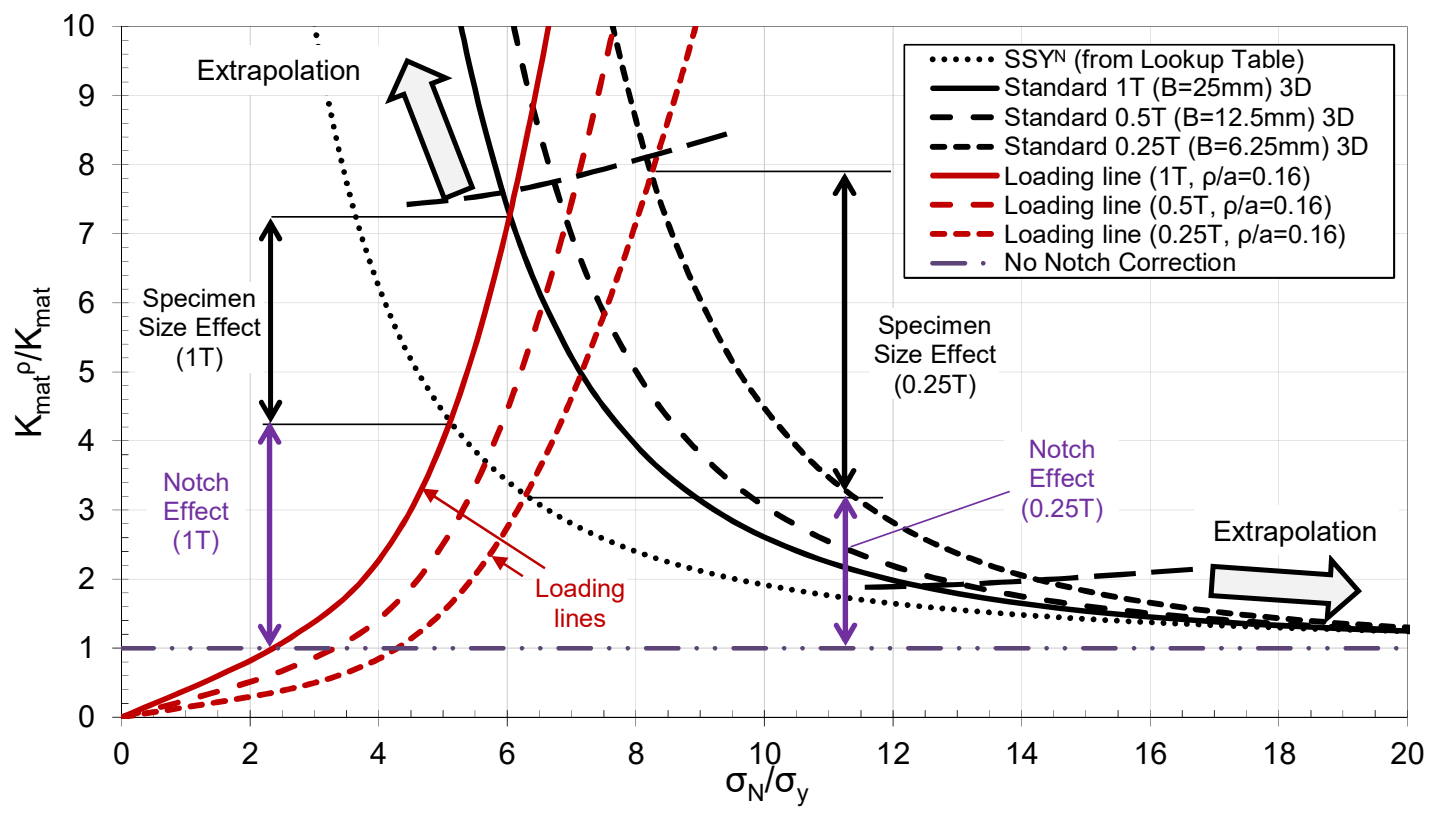

Figure 6: Failure loci derived using Weibull stress analysis for different sizes of notched CT specimens and for SSY for a notch

The specimen size effect was attributed to two different types of constraint loss in [12]: out-of-plane constraint loss (a thickness effect), and the in-plane constraint loss due to large scale yielding. It is not possible to deduce from the results presented in Figure 6 whether the out-of-plane or the in-plane constraint loss is the primary cause of the specimen size effect, or whether both effects contribute in similar proportions, because both the thickness $B$ (which controls out-of-plane constraint loss) and the un-cracked ligament $b=W-a$ (which controls the in-plane constraint loss due to large scale yielding) change from one sized CT specimen to another.

For this reason, and as described previously, all FE models of standard thickness CT specimens were also analysed in plane strain, i.e. with boundary conditions imposed on the free surface to restrict outof-plane displacement. The resulting failure loci for the plane strain condition are shown in Figure 7. These are positioned below the failure loci for the 3D analyses, and much closer to the SSY ${ }^{\mathrm{N}}$ condition. This indicates that the overall size effect is dominated by out-of-plane constraint loss.

Loading lines for the $1 \mathrm{~T}$ and $0.25 \mathrm{~T}$ specimens with $\rho / a=0.16$ are also shown in Figure 7. A more detailed examination of the results can be undertaken by comparing the intersection of the loading lines with the various failure loci, and this approach has been used to show the relative contribution that each form of constraint loss contributes to the specimen size effect. Taking again the $0.25 \mathrm{~T}$ specimen with $\rho / a=0.16$ as an example, the loading curve intersects the $\mathrm{SSY}^{\mathrm{N}}$ failure locus at $K_{m a t}^{\rho} / K_{\text {mat }} \sim 3$, the $0.25 \mathrm{~T}$ plane strain failure locus at $K_{m a t}^{\rho} / K_{\text {mat }} \sim 4$ and the $0.25 \mathrm{~T} 3 \mathrm{D}$ failure locus at $K_{m a t}^{\rho} / K_{\text {mat }} \sim 8$. This confirms that the vast majority of the specimen size effect is due to out-of-plane constraint loss, with in-plane constraint loss contributing very little to the specimen size effect for the $0.25 \mathrm{~T}$ specimen. The results in Figure 7 also indicate that there is a small difference between the SSY $^{\mathrm{N}}$ solution and the 1T plane strain solution: the cause of this difference is discussed later in Section 4.3. 


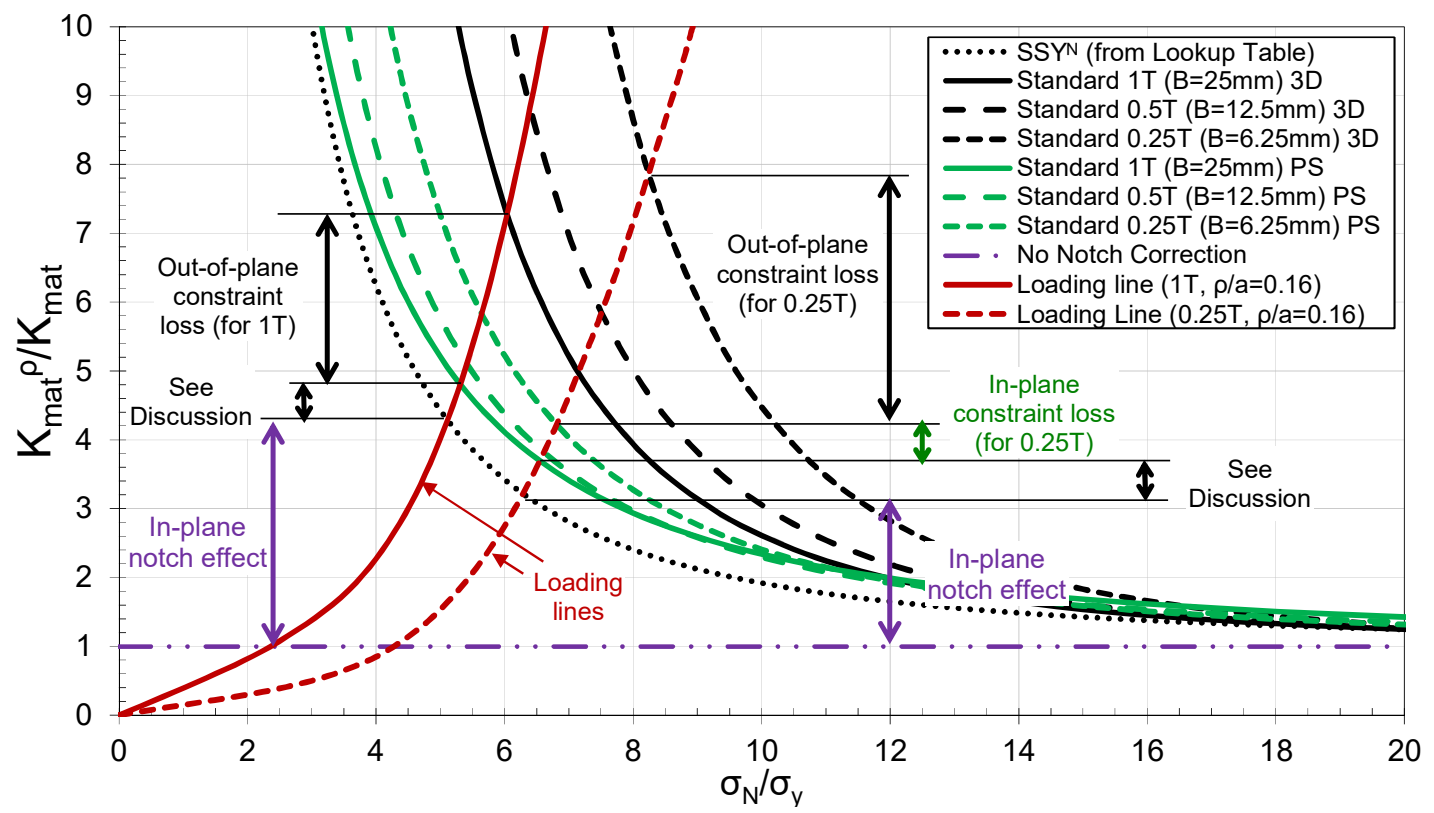

Figure 7: Failure loci derived using Weibull stress analysis for 2D plane strain analyses (green) compared with 3D analyses (black)

Table 2 provides a summary of the different type of size and geometry effects that can occur in notched and pre-cracked specimens and structures. NFAD approaches in the literature typically address only the top row of Table 2, with the approach in [12] using $\sigma_{N}$ to characterise the in-plane mechanical (constraint loss) effect of notch radius on $K_{\text {mat }}^{\rho}$. The remaining rows in Table 2 show other size effects which can occur in the pre-cracked specimens, and whose magnitude can be amplified for notched specimens due to the presence of the notch radius. For example, the out-ofplane mechanical constraint loss effect for pre-cracked specimens is not significant for standard 1T CT specimens. However as shown by the results in this paper, this effect becomes significant in a notched specimen of the same size. Conversely, the in-plane mechanical constraint loss caused by geometry and loading effects that is typically characterised by the T-stress or Q-parameter does not appear to have been significantly amplified by the presence of the notch for the conditions studied in this work. Further work would be beneficial to confirm whether this conclusion holds more widely. It has previously been proposed that this form of in-plane constraint loss is independent of the notch radius effect and can be treated separately to the in-plane notch radius effect $[11,30]$.

Table 2: Summary of Size and Geometry Effects

\begin{tabular}{|c|c|c|c|}
\hline $\begin{array}{c}\text { In-Plane or } \\
\text { Out Of Plane }\end{array}$ & Type of Effect & Cause of Effect & Analysis Approach \\
\hline \multirow{2}{*}{ In-Plane } & Mechanical & Notch Radius & $\sigma_{N}$ \\
\cline { 3 - 4 } & & Geometry \& Loading & T-Stress (contained yielding) \\
\cline { 3 - 4 } & & Q (extended yielding) \\
\hline \multirow{2}{*}{ Out-of-Plane } & Mechanical & Plane stress vs. plane strain & No standardised approach \\
\cline { 3 - 4 } & Microstructural & Crack front length & Weakest Link statistics \\
\hline
\end{tabular}

The last row of Table 2 refers to an out-of-plane microstructural effect which is relevant only for cleavage fracture. For thick specimens, a longer crack front length and hence larger plastic zone volume increases the probability of sampling a microstructural feature capable of triggering cleavage fracture compared with a thin specimen. This effect is incorporated into Figure 7 through the use of a 
$K_{\text {mat }}$ value specific to the crack front length for the relevant CT specimen geometry, defined by Equation 6.

The results in Figure 7 show that $K_{m a t}^{\rho}$ values measured using standard thickness CT specimens will be non-conservative if used in an NFAD assessment of a structure where the out-of-plane constraint loss is less significant. For example, a long surface-breaking non-sharp defect in a structure would be predominantly in plane strain at the deepest part of the notch, but tests on standard thickness CT

specimens of the same material may exhibit much higher values of $K_{m a t}^{\rho}$ than in the structure due to the out-of-plane constraint loss in the CT specimens. Using $K_{m a t}^{\rho}$ values from these CT tests to assess failure in a structure where plane strain conditions dominate would result in a non-conservative NFAD assessment. This indicates that minimum thickness requirements specified in fracture toughness testing standards such as [5] for ensuring plane strain conditions dominate in test specimens are only applicable to specimens with fatigue pre-cracks. It is therefore important to ensure that the out-of-plane constraint loss in the notched CT test specimen is properly considered. The following section considers whether testing CT specimens with a greater thickness can reduce the out-of-plane constraint loss in the test specimen.

\subsection{Double thickness CT specimens}

As described previously, double thickness CT specimens of each size (1T, $0.5 \mathrm{~T}$ and $0.25 \mathrm{~T}$ ) were also modelled and analysed. The results, shown in Figure 8, show a significant reduction in effective toughness for all specimen sizes, with the difference between the 3D analyses and SSY for a notch also being significantly reduced. The intersection of the loading lines with the failure loci show that the specimen size effect is significantly reduced in the double thickness CT specimens compared with the standard thickness CT specimen results shown in Figure 6.

Plane strain models of the double-thickness CT specimens were also analysed for comparison with the 3D analyses. The results in Figure 9 show that the failure loci for the 3D double-thickness specimens coincide precisely with the plane strain analyses for the $1 \mathrm{~T}$ and $0.5 \mathrm{~T}$ specimens, and match closely with the plane strain analyses for the $0.25 \mathrm{~T}$ specimens. This is a significant change from the differences observed for standard-thickness CT specimens in Figure 7 where the 3D and plane strain results were significantly different. The results in Figure 9 indicate that, for the material considered in this paper, doubling the thickness $B$ of the CT specimen results in plane strain conditions being sufficiently dominant to eliminate out-of-plane constraint loss in the CT specimen. 


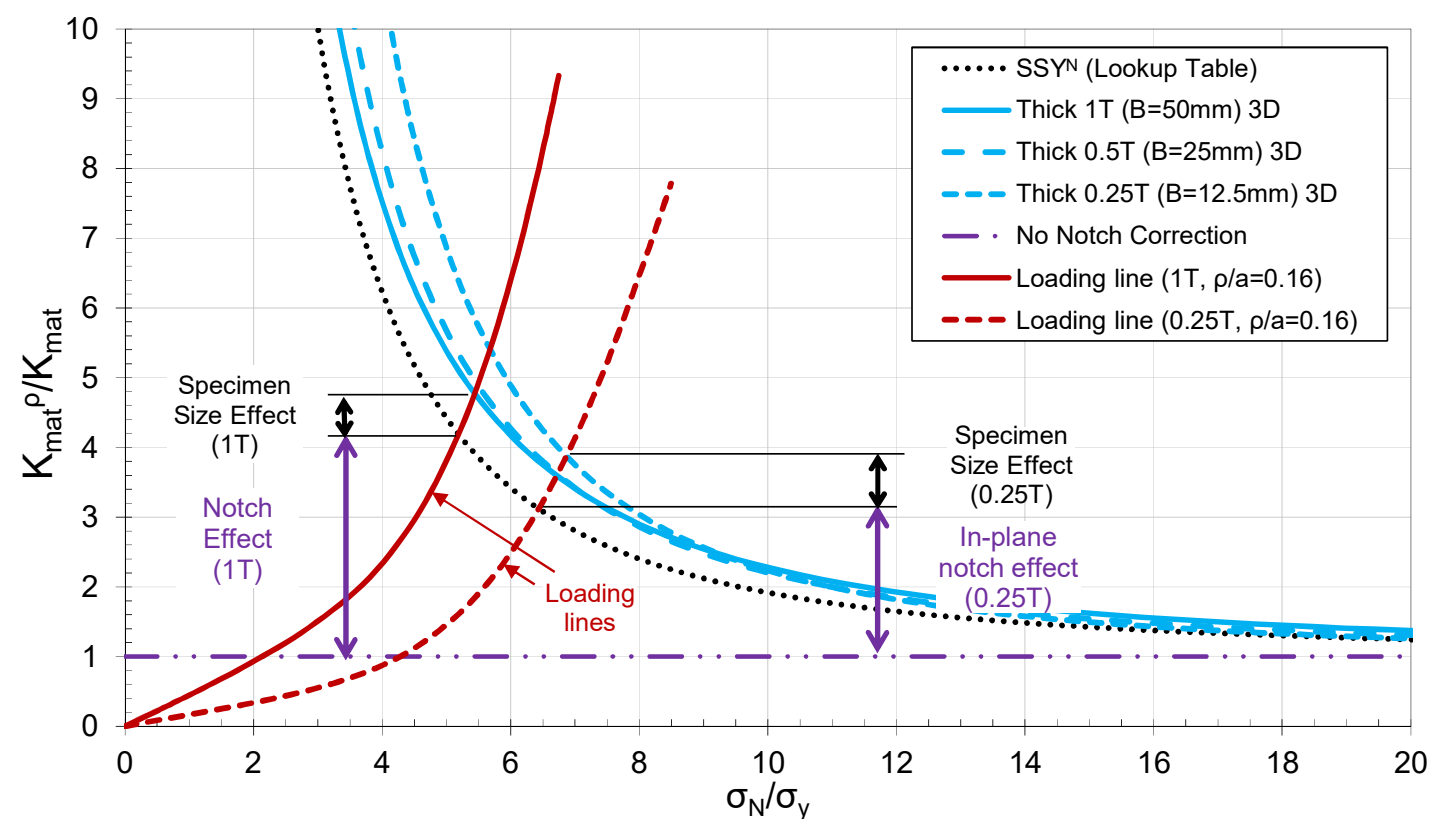

Figure 8: Comparison of failure loci for double-thickness CT specimens
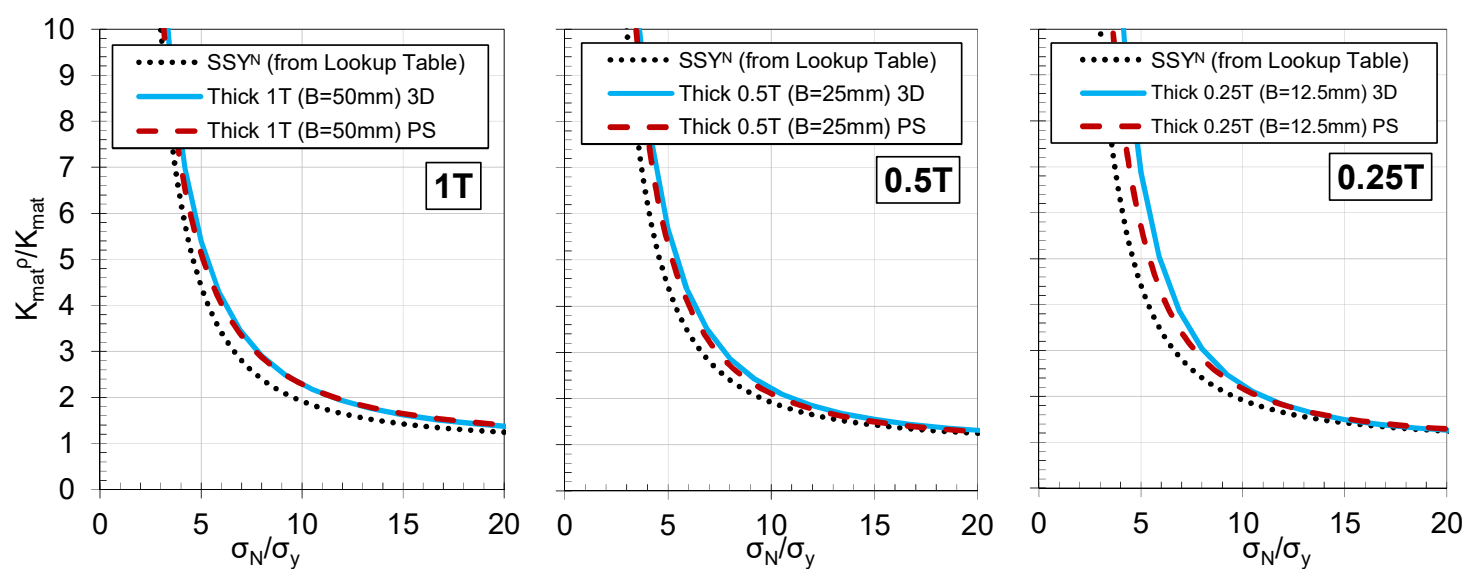

Figure 9: Comparison of 3D and plane strain solutions for the double-thickness CT specimens

\subsection{Lookup table and selection of strain hardening exponent $n$}

A common trend noted throughout Figures 7-9 is the existence of a small difference between the $\mathrm{SSY}^{\mathrm{N}}$ failure locus and those of the plane strain or thick 1T specimens. Closer inspection of the methodology used to generate the lookup table presented in [12] shows that the stress-strain curve was defined using tensile properties defined according to:

$\varepsilon / \varepsilon_{0}=\left(\sigma / \sigma_{0}\right)$ for $\varepsilon \leq \varepsilon_{0}$

$\varepsilon / \varepsilon_{0}=\left(\sigma / \sigma_{0}\right)^{n}$ for $\varepsilon>\varepsilon_{0}$

where $\varepsilon$ is the total true strain and $\sigma_{0}$ is the limit of proportionality being related to $\varepsilon_{0}$ through the relationship $\varepsilon_{0}=\sigma_{0} / E$. The shape of the stress-strain curve according to Equations 8 and 9 is slightly different to that used in the modelling work presented in this paper, which uses experimentally measured stress-strain data at low strains and an extrapolated curve based on a Ramberg-Osgood fit at higher strains. An $n$ value of 6.4 was found to provide the best curve fit over the range $0.01<\varepsilon<0.1$, a strain range recommended in [30] for modelling sharp cracks where the high strain region ahead of 
the crack tip controls fracture. However, for strains below this range, the use of $n=6.4$ in Equations 8 and 9 increasingly over-predicts the stress around the yield point compared to the test data, as shown in Figure 10. Although such an over-prediction is not usually significant when modelling sharp cracks, this may not necessarily be the case for blunt notches where the stresses controlling fracture are lower; it may therefore be necessary to give greater weight to an accurate curve fit at lower strains than those recommended for modelling cracks.
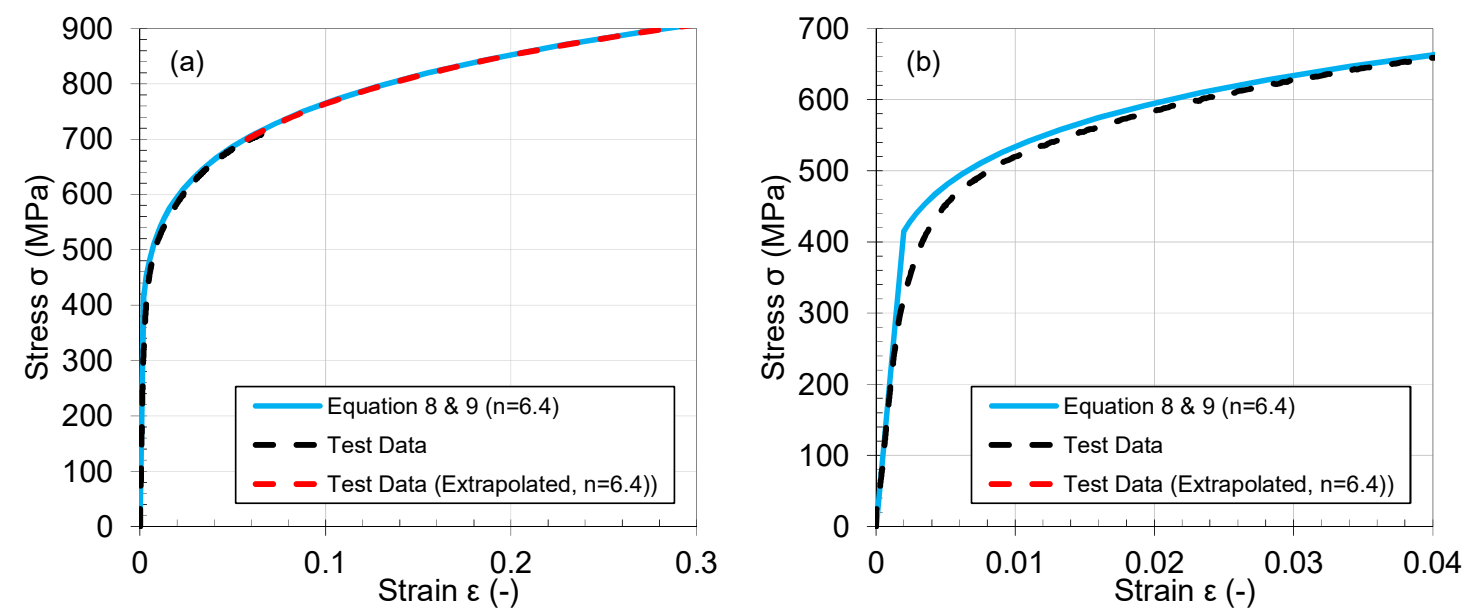

Figure 10: Comparison of test data with curve fit defined using $n=6.4$ in Equations 8 and 9, (a) strains up to 0.3 , (b) close up of yield point

To investigate the sensitivity of the $\mathrm{SSY}^{\mathrm{N}}$ failure locus to the value of $\mathrm{n}$ used in the lookup table, Equations 8 and 9 were fitted to the test data over a lower range, arbitrarily chosen as $0.005<\varepsilon<0.05$. As can be seen in Figure 11, $n=5.8$ was found to give a reasonable fit to the test data in this range, but at the expense of accuracy at larger strains. There remains some over-estimation of stresses at the yield point, however this is less than shown in Figure 10. Based on $m=20$ and $n=5.8$, the lookup table in [12] gives values of $\gamma$ and $l$ of 83.68 and 1.88 respectively.
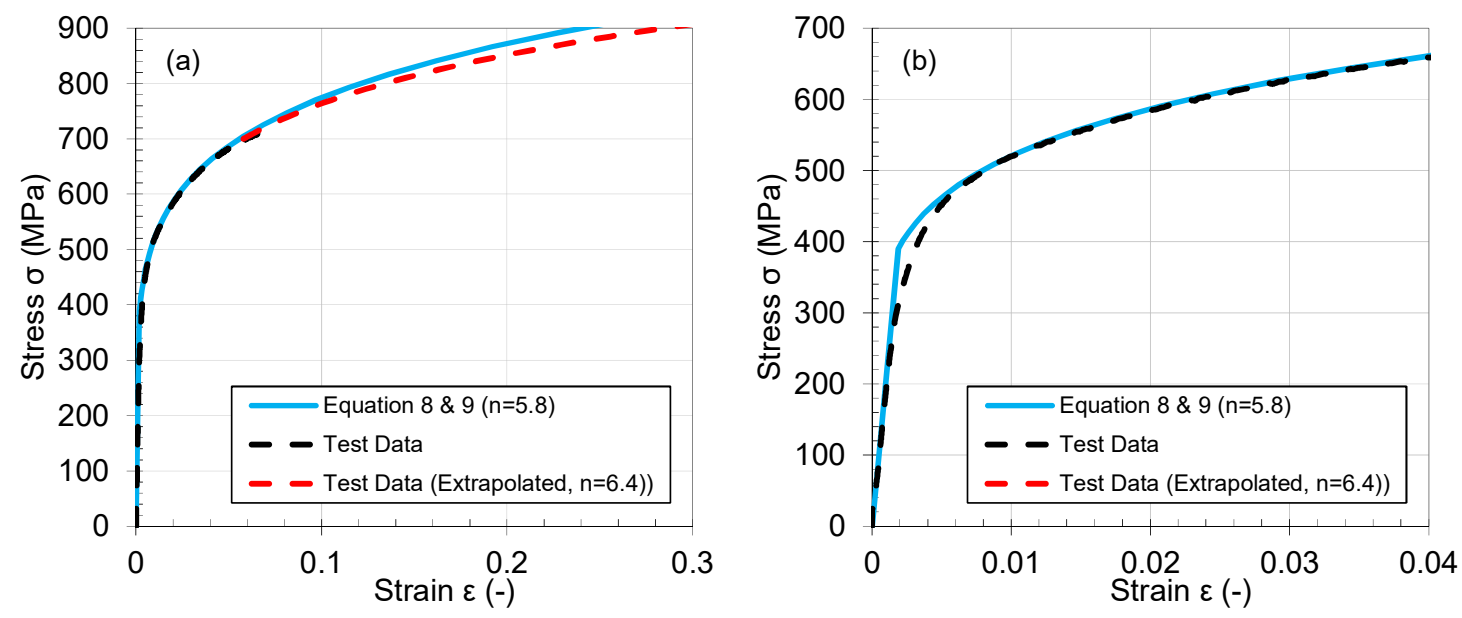

Figure 11: Comparison of test data with curve fit defined using $n=5.8$ in Equations 8 and 9, (a) strains up to 0.3 , (b) close up of yield point

Figure 12 and Figure 13 show the same results for the standard and double thickness CT specimen, this time compared to the $\mathrm{SSY}^{\mathrm{N}}$ solution based on $\mathrm{n}=5.8$ rather than $\mathrm{n}=6.4$. The $\mathrm{SSY}^{\mathrm{N}}$ solution is much closer to the failure locus for the $1 \mathrm{~T}$ solution for both the double thickness $3 \mathrm{D}$ analysis and the 
standard thickness plane strain analysis. Noting the sensitivity of the $\mathrm{SSY}^{\mathrm{N}}$ solution to the stress-strain curve, the remaining small differences between the $\mathrm{SSY}^{\mathrm{N}}$ locus and those for the $1 \mathrm{~T}$ solutions are likely to be due to the remaining difference between the stress-strain curve of the test data and of the fit shown in Figure 11(b).

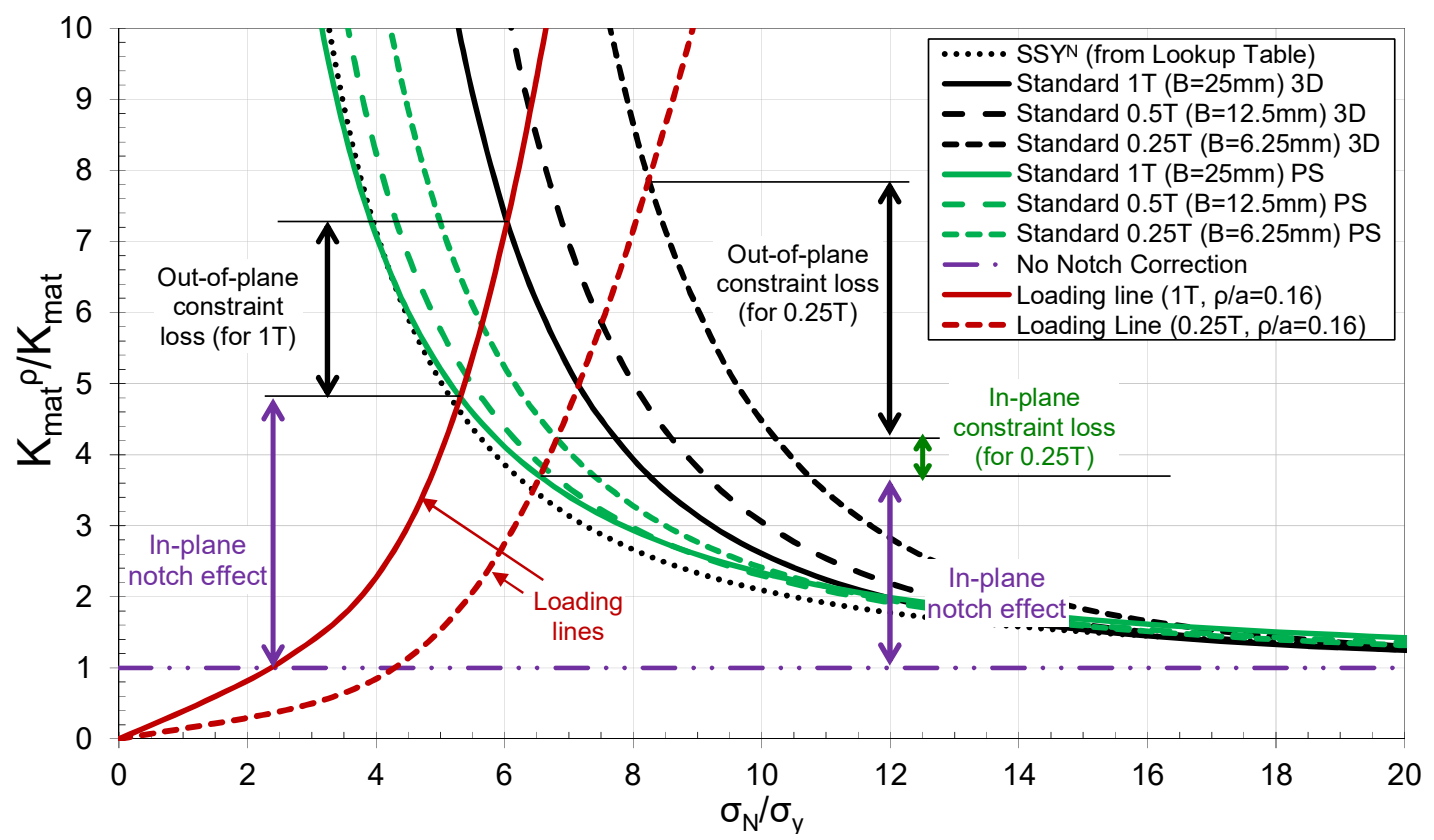

Figure 12: Failure loci for standard thickness CT specimens compared with the $\mathrm{SSY}^{\mathrm{N}}$ solution based on $\mathrm{n}=5.8$

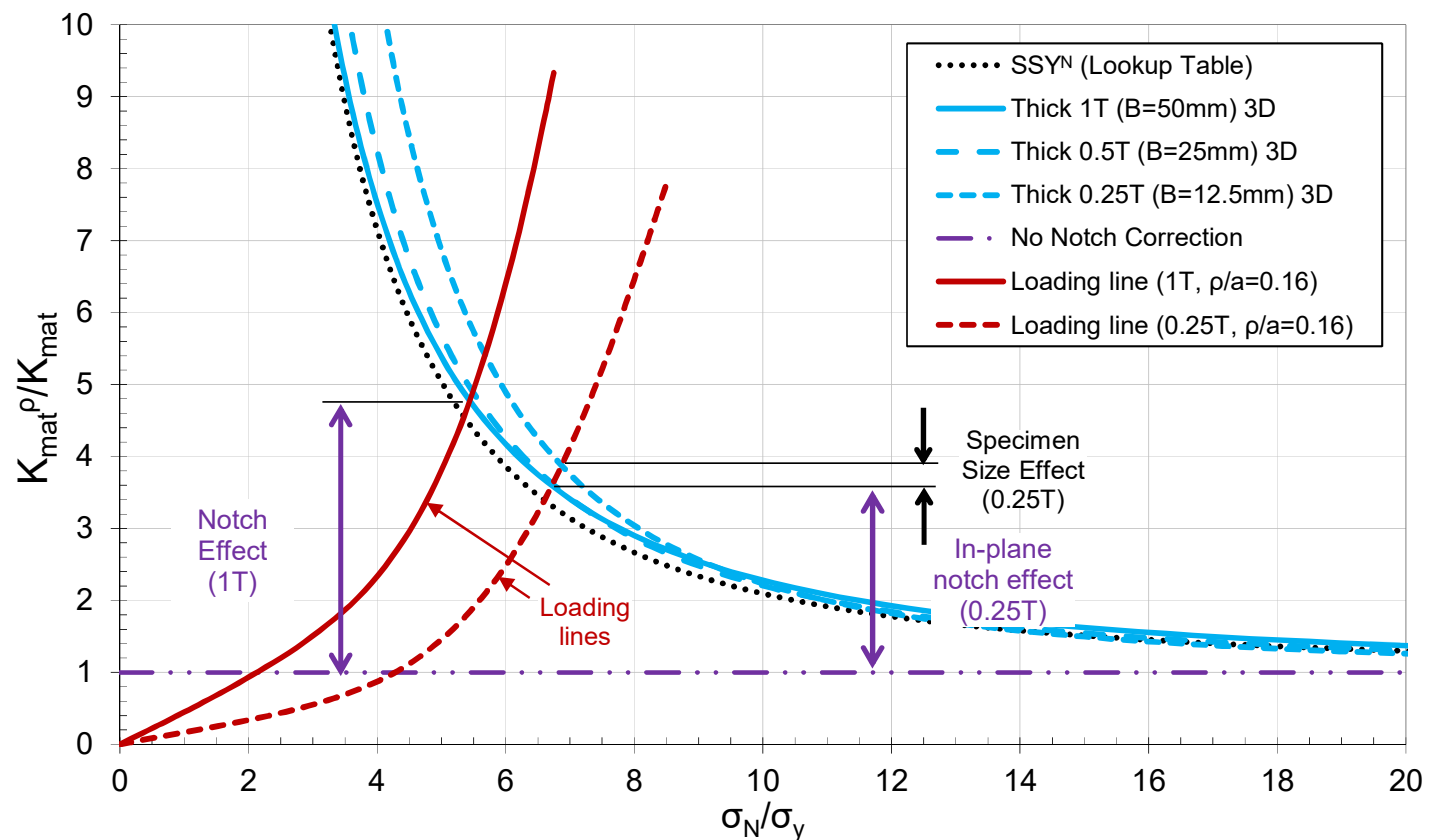

Figure 13: Failure loci for double thickness CT specimens compared with the $\mathrm{SSY}^{\mathrm{N}}$ solution based on $n=5.8$ 
The overall contribution of the out-of-plane and in-plane constraint loss is much clearer in both Figures. From Figure 13 it is evident that specimen size effects have been almost completely removed from the double-thickness $1 \mathrm{~T}$ and $0.5 \mathrm{~T}$ specimens. Hence it can be concluded that the $K_{m a t}^{\rho}$ value that would be measured using these specimens will be a true measure of the in-plane notch effect alone.

The results from Figure 12 and Figure 13 are combined in Figure 14. This shows predicted values of $K_{m a t}^{\rho} / K_{m a t}$ at failure (i.e. the intersection of the loading line with the relevant failure locus) for $\rho / a=0.16$, with the relative contributions shown for each of the mechanical size and geometry effects listed in Table 2. From this Figure it is clear the extent to which $K_{m a t}^{\rho}$ values measured on standardthickness CT specimens are increased by out-of-plane constraint loss for the material considered in this study.

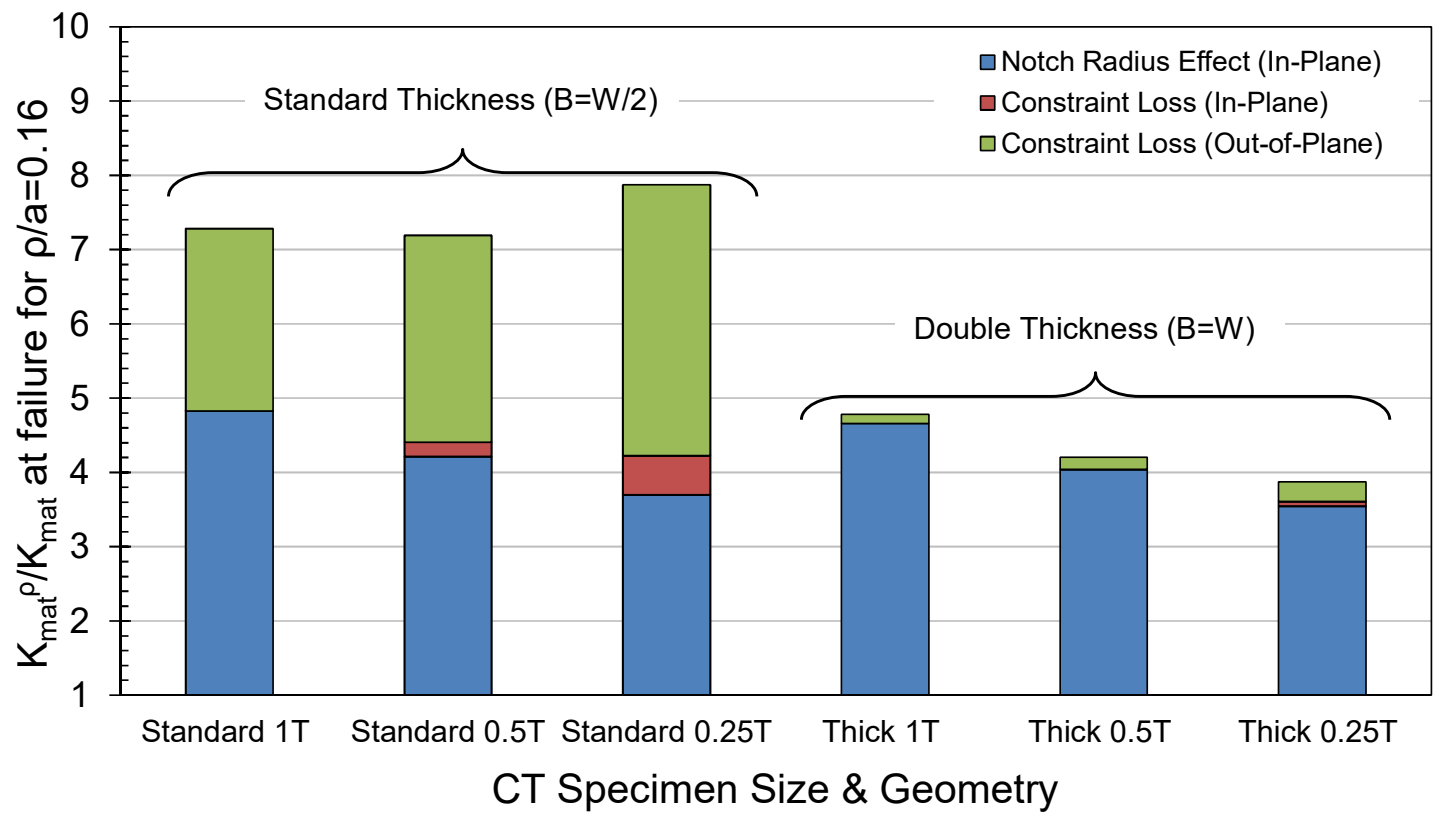

Figure 14: $K_{m a t}^{\rho} / K_{m a t}$ at failure for each $\mathrm{CT}$ specimen modelled, showing the relative proportion contributed by differing forms of constraint loss.

\section{CONCLUSIONS}

The main conclusions of this work are as follows:

- The effective toughness $K_{\text {mat }}^{\rho}$ measured using CT specimens containing a U-notch is dependent on specimen thickness $B$, over and above the microstructural weakest link effect arising from differences in the volume of the plastic zone which is accounted for in the analysis.

- $\quad K_{m a t}^{\rho}$ is a function of both the in-plane effect of the notch radius and an out-of-plane constraint loss which itself is enhanced by the presence of the notch radius. This out-of-plane constraint loss can be more significant than the in-plane effect of the notch radius alone.

- The use of experimentally measured $K_{m a t}^{\rho}$ values in an NFAD assessment of a structure may be non-conservative if the out-of-plane constraint loss in the CT specimen is more significant than in the structure. 
- Minimum thickness requirements specified in fracture toughness testing standards for ensuring plane strain conditions dominate are only applicable to specimens with fatigue precracks.

- For the material considered in this paper, doubling the thickness $B$ of the CT specimen resulted in plane strain conditions being sufficiently dominant to eliminate out-of-plane constraint loss in the CT specimen.

- For the notched $\mathrm{CT}$ specimens with $\mathrm{a} / \mathrm{W}=0.5$ modelled in this paper, there was no indication that the presence of the notch radius enhanced in-plane constraint loss effects due to crack depth and loading type that is typically characterised by the T-stress or Q-parameter. Further work would be beneficial to confirm whether this conclusion holds more widely.

- When using the lookup table in [12] to obtain the material parameters $\gamma$ and $l$ that describe the $\mathrm{SSY}^{\mathrm{N}}$ failure locus, the value of $n$ used should be that which provides a good curve fit at relatively low strain ranges on the stress-strain curve.

\section{ACKNOWLEDGEMENTS}

This paper is published with the permission of Amec Foster Wheeler, EDF Energy and the UK's National Nuclear Laboratory (NNL). This work was funded by EDF Energy's R6 development programme and NNL.

\section{REFERENCES}

1. R6 - Revision 4: assessment of the integrity of structures containing defects, Amendment 11: March 2015. EDF Energy, Gloucester, UK.

2. BSI. BS7910:2013+A1:2015, incorporating corrigenda Nos. 1 and 2, 2016: Guide on methods for assessing the integrity of flaws in metallic structures. British Standards Institution, 2016.

3. API 579-1/ASME FFS-1, Fitness-for-Service, jointly published by the American Petroleum Institute and the American Society for Mechanical Engineers, June 2016.

4. BSI. BS 7448-1: fracture mechanics toughness tests - Part 1: method for determination of KIC, critical CTOD and critical J values of metallic materials. British Standards Institution; 1999.

5. ASTM E1820-11. Standard Test Method for Measurement of Fracture Toughness. ASTM, 2011.

6. ESIS. ESIS P2-92: ESIS procedure for determining the fracture behaviour of materials; 1992.

7. Wang WQ, Li AJ, Li PN, Ju DY. Engineering approach for notch elastic-plastic fracture analysis. International Journal of Pressure Vessels and Piping 1994;60:1-16.

8. Smith E. Fracture initiation at the root of a blunt flaw: description in terms of $\mathrm{Kr}-\mathrm{Lr}$ failure assessment curves. International Journal of Pressure Vessels and Piping 1999;76(11):799-800.

9. Matvienko YG. Local fracture criterion to describe failure assessment diagrams for a body with a crack/notch. International Journal of Fracture 2003;124:107-12.

10. Cicero S, Gutiérrez-Solana F, Horn AJ. Experimental analysis of differences in mechanical behaviour of cracked and notched specimens in a ferritic-pearlitic steel: Considerations about the notch effect on structural integrity. Engineering Failure Analysis 2009;16:2450-66.

11. Cicero S, Gutiérrez-Solana F, Álvarez JA. Structural integrity assessment of components subjected to low constraint conditions. Engineering Fracture Mechanics 2008;75(10):3038-59.

12. Horn AJ, Sherry AH. An engineering assessment methodology for non-sharp defects in steel structures - Part I: procedure development. International Journal of Pressure Vessels and Piping 2012;89:137-50.

13. Han J-J, Larrosa NO, Kim Y-J, Ainsworth RA. Blunt defect assessment in the framework of the failure assessment diagram. International Journal of Pressure Vessels and Piping 2016;146:39-54. 
14. Horn AJ, Budden PJ. Development of test guidance for single edge notch bend fracture toughness specimens containing notches instead of fatigue pre-cracks. Proceedings of the ASME 2015 Pressure Vessels and Piping Conference, July 19-23, Boston, Massachusetts, USA. PVP201545474.

15. Horn AJ, Budden PJ. Development of test guidance for compact tension fracture toughness specimens containing notches instead of fatigue pre-cracks. Proceedings of the $23^{\text {rd }}$ Conference on Structural Mechanics in Reactor Technology (SMiRT-23), Manchester, UK, August 10-14, 2015. Paper no. 287.

16. Cicero S, Garcia T, Madrazo V, Cuervo J, Ruiz E, Gutierrez-Solana F. Analysing the Notch Effect within the Ductile-to-Brittle Transition Zone of S275JR Steel. Proceedings of the ASME 2013 Pressure Vessels and Piping Conference, July 14-18, Paris, France. PVP2013-97017.

17. Cicero S, Madrazo V, Garcia T, Cuervo J, Ruiz E. On the Notch Effect in Load Bearing Capacity, Apparent Fracture Toughness and Fracture Mechanisms of Polymer PMMA, Aluminium Alloy A17075-T651 and Structural Steels S275JR and S355J2. Engineering Failure Analysis 2013;29:108-121.

18. Cicero S, Gutiérrez-Solana F, Álvarez JA. Structural Integrity Assessment of Components Subjected to Low Constraint Conditions. Engineering Fracture Mechanics 2008;75:3038-3059.

19. Landes JD, Begley JA. Experimental Methods for Elastic-Plastic and Post-Yield Fracture Toughness Measurements, in Post-yield Fracture Mechanics, D.G.H. Latzko, Editor. Applied Science Publishers Ltd, London. 1979; 211-253.

20. Livieri P. Use of J-integral to Predict Static Failures in Sharp V-notches and Rounded U-Notches. Engineering Fracture Mechanics 2008;75:1779-1793.

21. Barati E, Berto F. Fracture Assessment of U-notches Under Mode I Loading By Means of Critical Value of the J-integral. Procedia Engineering 2011;10:807-812

22. Horn AJ, Sherry AH. Prediction of cleavage fracture from non-sharp defects using the Weibull stress based toughness scaling model. International Journal of Pressure Vessels and Piping 2010;87:670-80.

23. Shin CS. A discussion on various estimations of elastic stress distributions and stress concentration factors for sharp edge notches. International Journal of Fatigue, 1986;8(4):235-237.

24. Creager M, Paris PC. Elastic field equations for blunt cracks with reference to stress corrosion cracking. International Journal of Fracture Mechanics, 1967;3:247-252.

25. Kim JS, Larrosa NO, Horn AJ, Kim YJ, Ainsworth RA. Notch Bluntness Effects on Fracture Toughness of a Modified S690 Steel at $150^{\circ} \mathrm{C}$. Submitted to Engineering Fracture Mechanics in October 2016.

26. Beremin FM. A Local Criterion for Cleavage Fracture of a Nuclear Pressure Vessel Steel. Metallurgical Transactions A 1983;14A,2277-2287.

27. Gao X, Ruggieri C, Dodds Jr RH. Calibration of Weibull Stress Parameters using Fracture Toughness Data. International Journal of Fracture 1998;92(2),175-200.

28. ABAQUS 6.12. ABAQUS Documentation, Dassault Systemes, Providence, RI, USA.

29. ASTM E1921-11a. Standard test method for determination of reference temperature, $\mathrm{T}_{0}$, for ferritic steels in the transition region. ASTM, 2011.

30. Sherry AH, Wilkes MA, Beardsmore DW, Lidbury DPG. Material constraint parameters for the assessment of shallow defects in structural components - Part I: Parameter solutions. Engineering Fracture Mechanics 2005;72:2373-2395. 